\title{
Malqui-Machay: cronología del descubrimiento, validación científica, empoderamiento social y puesta en valor
}

Tamara Estupiñán Viteri

\section{(2) OpenEdition}

Journals

Edición electrónica

URL: http://journals.openedition.org/bifea/1370

DOI: $10.4000 /$ bifea. 1370

ISSN: 2076-5827

Editor

Institut Français d'Études Andines

Edición impresa

Fecha de publicación: 1 diciembre 2011

Paginación: 593-597

ISSN: 0303-7495

Referencia electrónica

Tamara Estupiñán Viteri, « Malqui-Machay: cronología del descubrimiento, validación científica, empoderamiento social y puesta en valor », Bulletin de l'Institut français d'études andines [En línea], 40

(3) | 2011, Publicado el 01 junio 2012, consultado el 07 noviembre 2020. URL : http://

journals.openedition.org/bifea/1370; DOI : https://doi.org/10.4000/bifea.1370

\section{(c) (i) (3)}

Les contenus du Bulletin de l'Institut français d'études andines sont mis à disposition selon les termes de la licence Creative Commons Attribution - Pas d'Utilisation Commerciale - Pas de Modification 4.0 International. 


\section{Malqui-Machay: cronología del descubrimiento, validación científica, empoderamiento social y puesta en valor}

\section{Tamara Estupiñán Viteri*}

El enigmático y fascinante sitio arqueológico inca de Malqui-Machay, ubicado en el flanco occidental de la provincia de Cotopaxi en el actual Cantón Sigchos, a 1020 metros de altitud, fue descubierto en dos expediciones.

El hallazgo no se realizó a través de técnicas tradicionales arqueológicas, sino mediante una rigurosa investigación etnohistórica de largo plazo en archivos, bibliotecas y trabajo de campo tanto en el Ecuador como en el extranjero.

En la primera expedición, que tuvo lugar el 16 de julio de 2004, se llegó a Malqui1, ruinas que están en la parte baja del valle del río Quindigua y el 26 de junio de 2010 se entró en Machay², una pequeña colina situada a pocos kilómetros de Malqui, en cuya cima se encuentran los vestigios más imponentes y que estarían ligados al culto que los incas tenían hacia sus ancestros progenitores.

* Becaria del Instituto Francés de Estudios Andinos (IFEA, UMIFRE 17, CNRS-MAE), miembro del Instituto Panamericano de Geografía e Historia del Ecuador. Email: tamaraestupinan@gmail.com

1 Esta expedición estuvo conformada por la historiadora Tamara Estupiñán Viteri, la arqueóloga Tamara Bray y Jaime Pástor Morris. La hacienda Malqui es de propiedad de los señores Luis Felipe Rivadeneira y Jorge Yarad.

2 Esta expedición estuvo conformada por Tamara Estupiñán Viteri, Jaime Pástor Morris, Tamara Bray, el geógrafo Bo Ramírez y a última hora se invitó a Eduardo Almeida, en razón de que él había hecho pocos meses antes el inventario arqueológico de la provincia de Cotopaxi, bajo una consultoría con el Instituto de Patrimonio Cultural del Ecuador, y desconocía por completo la existencia de MalquiMachay. La hacienda Machay hasta hace pocos años perteneció a la familia Moncayo Estupiñán. Actualmente la heredaron los miembros de la familia Moncayo Naranjo. En este punto se aclara que no existe ninguna vinculación de parentesco entre la familia Moncayo Estupiñán y la historiadora Estupiñán Viteri; el apellido común es coincidencia. 
La noticia oficial del descubrimiento de Malqui-Machay fue divulgada el 8 de abril de 2011, en el marco del Octogésimo Aniversario del Instituto Geográfico Militar del Ecuador y por primera vez para el mundo en el portal de Internet Latitude France y en el diario Le Monde, París, sección Sciences Décryptages 3.

La validación científica y social de Malqui-Machay provino del interés que el monumento despertó asociado a la hipótesis de que habría sido la última morada de Atahualpa, figura emblemática en la conquista española en los Andes y en el presente actual de la región, y básicamente de una intensa actividad de carácter multidiciplinario e interinstitucional (véase cuadro 1).

En efecto, después del descubrimiento de las ruinas, se realizaron trece expediciones con arqueólogos, antropólogos, historiadores, geógrafos, estudiosos del pasado ecuatoriano e inca, autoridades políticas, medios de comunicación internacional y local y la comunidad, quienes pudieron constatar in-situ que Malqui-Machay no era una construcción aleatoria, ni tampoco un cúmulo de piedras apiladas.

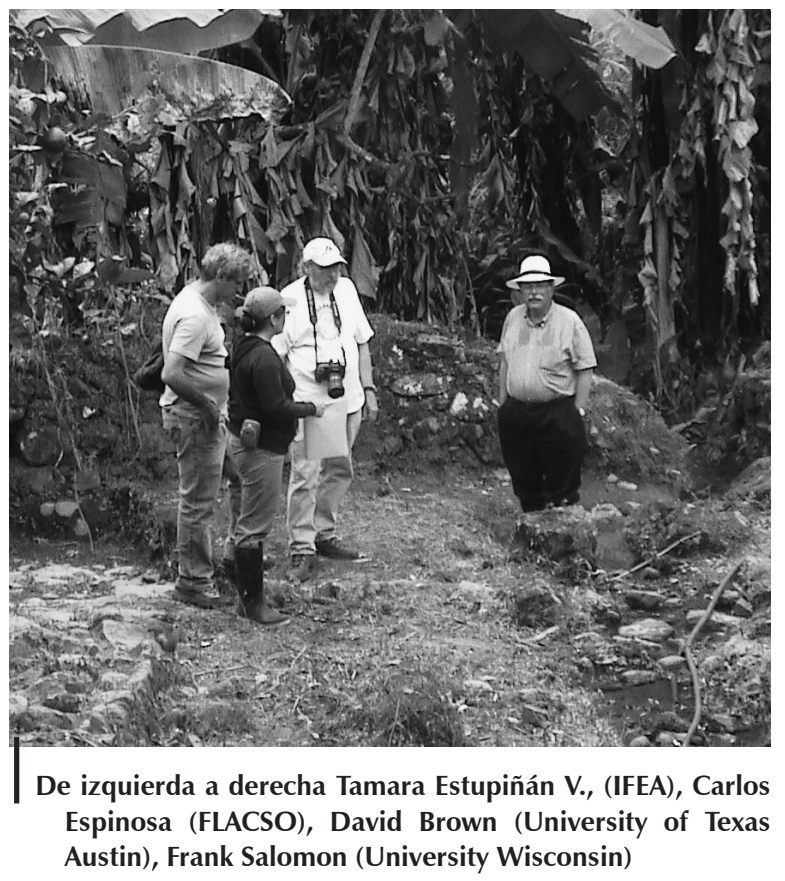

3 Se trata de la conferencia «Los Sigchos, el último refugio de los incas quiteños». Un video que retoma lo esencial de esta conferencia fue colocado en el portal del IFEA (véase www.ifeanet.org). Veáse en el portal de Latitude France (http://www.latitudefrance.org/Decouverte-en-Equateur-d-un. html). Artículo publicado en Le Monde bajo el título «Sur la piste de la momie d'Atahualpa, dernier empereur inca », el 16 de julio de 2011. De forma paralela se publicó un avance del descubrimiento en el Bulletin de l'Institut Français d'Études Andines, 2011. Como conferencia fue impartida en otro foros: V Encuentro de la Sección de Estudios Ecuatorianos de LASA, 1 de julio de 2011, FLACSOEcuador; Seminario Interdisciplinario Pisac 2011, Programa de Estudios Andinos, Perú, 5 julio de 2011; Instituto Francés de Estudios Andinos, Lima, 12 de julio de 2011. 
De hecho, a la luz de la evidencia arqueológica-arquitectónica, las descripciones de distintos Cronistas de Indias, dibujos de Guamán Poma de Ayala, literatura sobre la importancia del culto a los ancestros entre los incas y el plano topográfico levantado por el Instituto de Patrimonio Cultural del Ecuador sobre las ruinas ubicadas en Machay, se comprobó que las estructuras arquitectónicas, como la plaza trapezoidal, los posibles ushnu (asiento del inca) y pucullo (bóveda de enterramiento) recorren el camino del Sol ya que están orientadas de este a oeste, no de sur a norte. También se identificó un baño con un acueducto subterráneo que pasa por debajo de una plaza pequeña construida con piedra bien labrada, varios canales de agua en la superficie, veredas de piedra, un callejón de ingreso en forma de zigzag y un puente para cruzar el río que bordea el complejo.

Malqui-Machay también ha sido objeto de un proceso de empoderamiento social por parte de las fuerzas vivas de la provincia de Cotopaxi, en especial por la comunidad quichua parlante de la Sierra ecuatoriana, que realizó una toma simbólica y la primera peregrinación al monumento para, mediante sus prácticas ancestrales, bendecir la pachamama donde están asentadas las ruinas.

La noticia del descubrimiento sobre Malqui-Machay cautivó el interés de la prensa internacional y local, se produjo una suerte de efecto de arrastre en Internet; una simple consulta en los principales buscadores da cuenta de que son varios los documentales realizados sobre las ruinas y miles de miles las referencias que aluden a este monumento arqueológico único en los Andes y que nunca antes había sido registrado por la historia y la arqueología.

El Estado Ecuatoriano, de su parte, se hizo presente al incluir en el presupuesto del año 2012, una partida específica para Malqui-Machay, a través del Programa de protección y recuperación del Patrimonio Cultural de Ecuador, Préstamo BID EC-L1097.

Con el compromiso firme del Ministerio Coordinador de Patrimonio del Ecuador, el apoyo científico de Francia, a través del IFEA, y la participación activa de la comunidad del GAD Sigchos, está previsto iniciar la investigación arqueológica en junio de 2012, reto que asumirá la arqueóloga franco-ecuatoriana, Catherine Lara, de la Universidad de la Sorbone, París.

\section{Referencia citada}

ESTUPIÑÁN, T., 2011 - Los Sigchos, el último refugio de los incas quiteños. Una propuesta preliminar. Bulletin de l'Institut Français d'Études Andines, 40 (1): 191-204; Lima. 


\begin{tabular}{|c|c|c|c|c|c|c|c|c|}
\hline $\begin{array}{l}\mathscr{0} \\
\frac{0}{0} \\
\text { 운 }\end{array}$ & 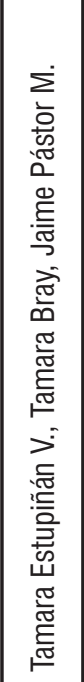 & 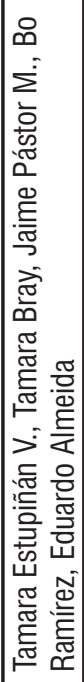 & 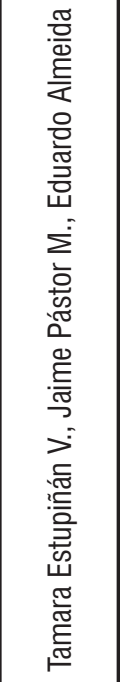 & 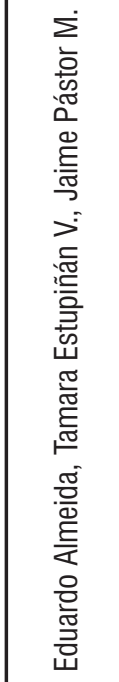 & 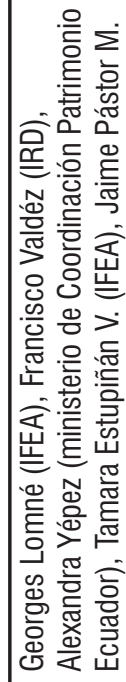 & 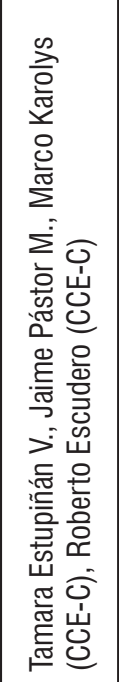 & 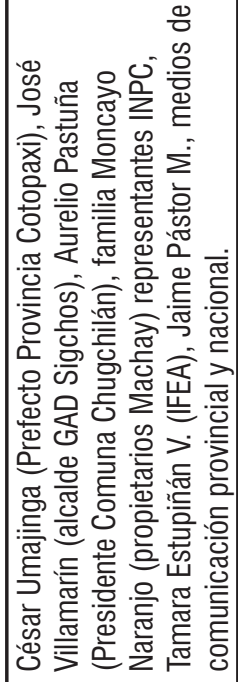 & 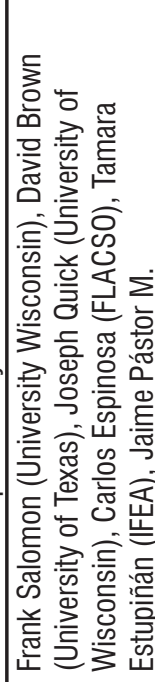 \\
\hline 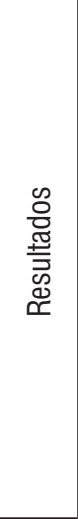 & 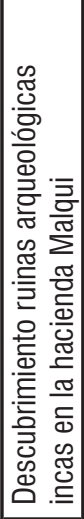 & 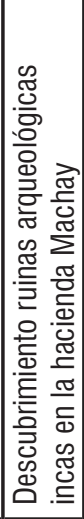 & 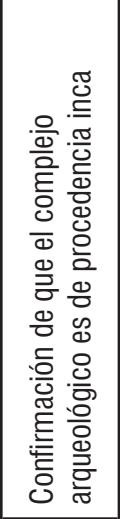 & 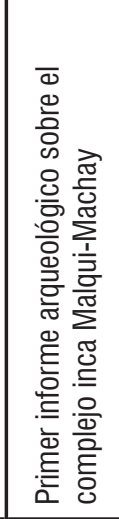 & 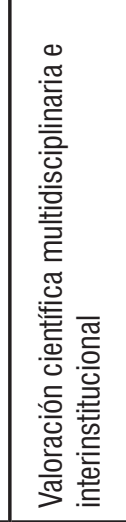 & 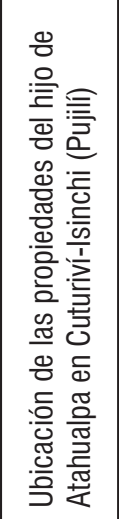 & 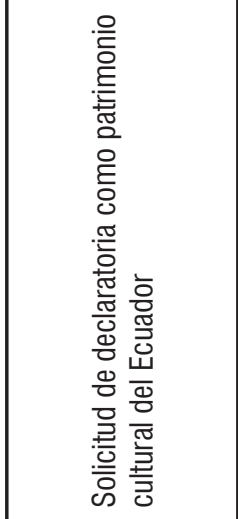 & 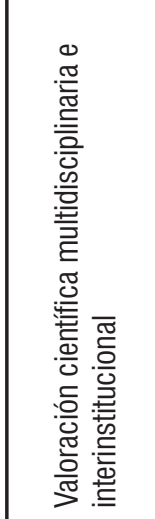 \\
\hline 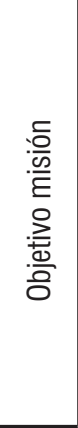 & 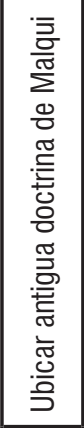 & 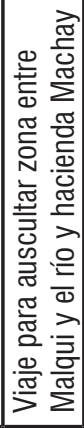 & 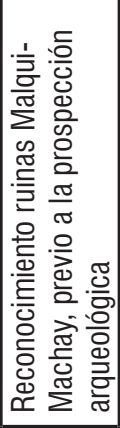 & 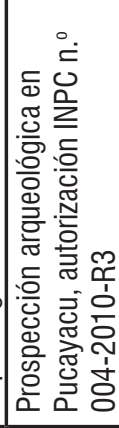 & 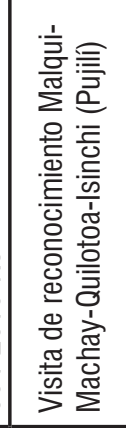 & 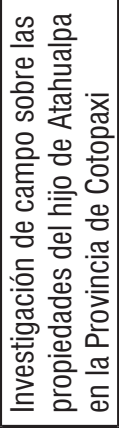 & 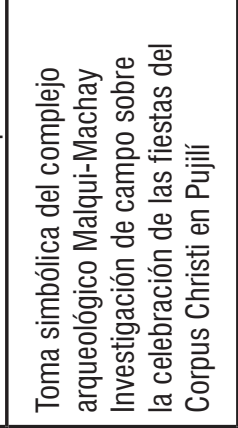 & 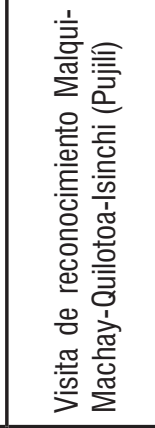 \\
\hline 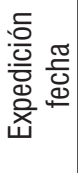 & 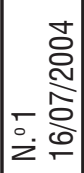 & 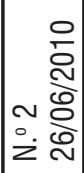 & 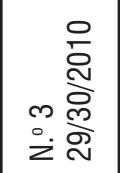 & 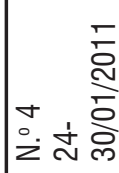 & 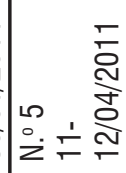 & 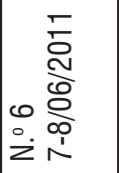 & 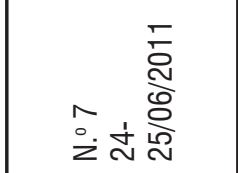 & 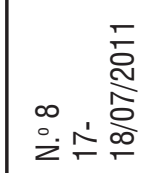 \\
\hline
\end{tabular}




\begin{tabular}{|c|c|c|c|c|c|c|}
\hline 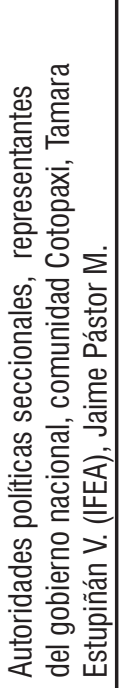 & 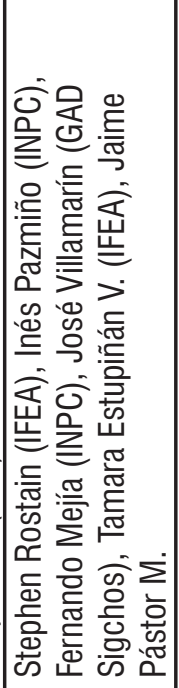 & 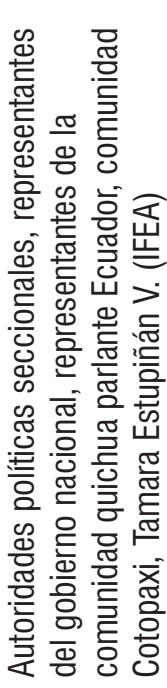 & 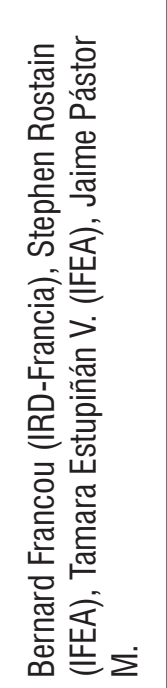 & 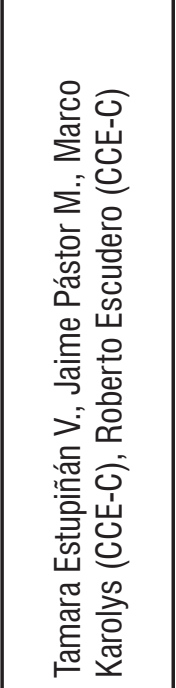 & 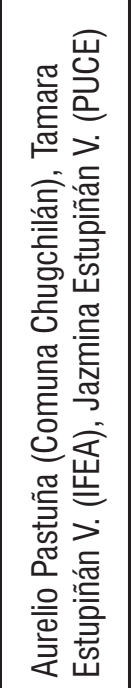 & 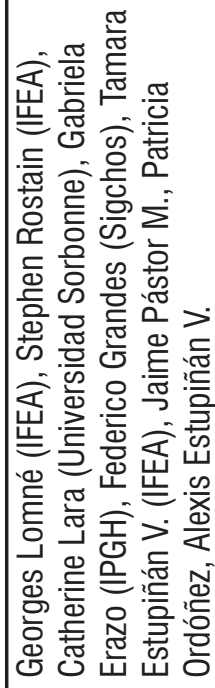 \\
\hline 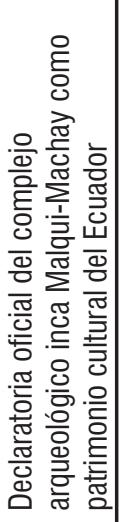 & 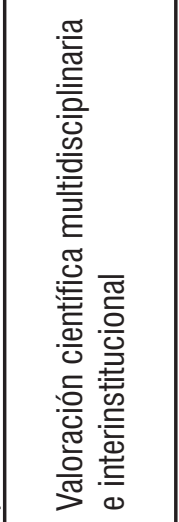 & 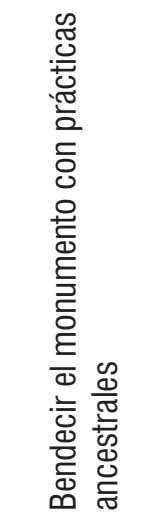 & 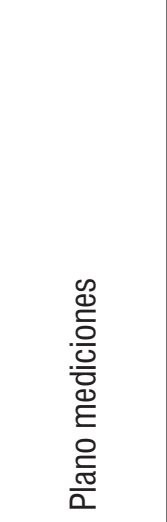 & 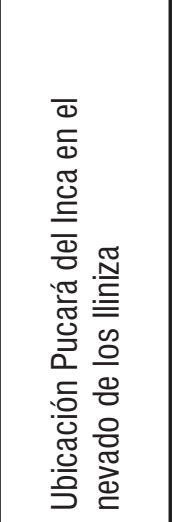 & 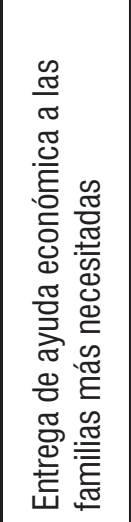 & 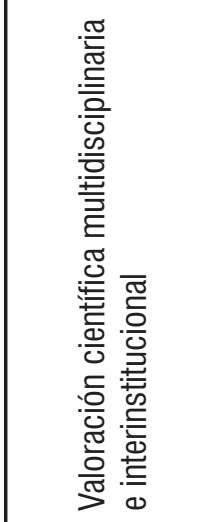 \\
\hline 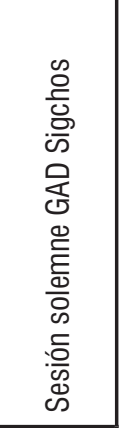 & 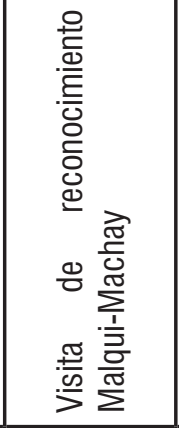 & 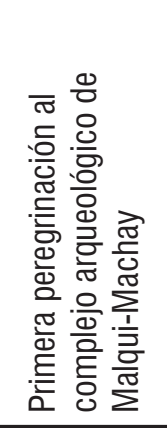 & 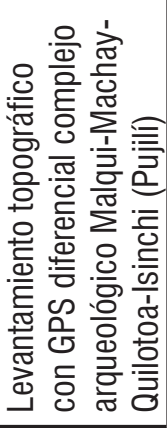 & 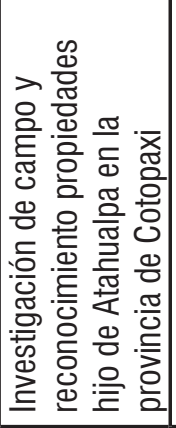 & 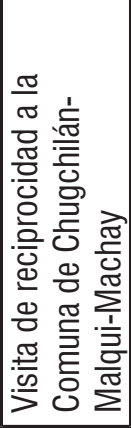 & 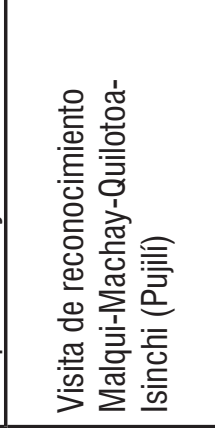 \\
\hline 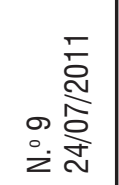 & 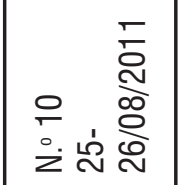 & 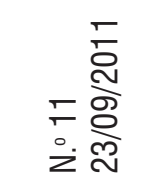 & 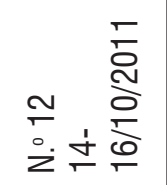 & 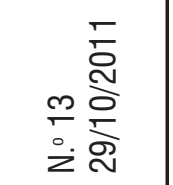 & 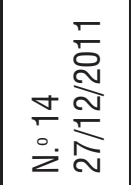 & 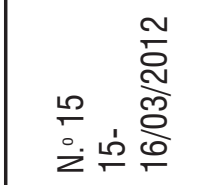 \\
\hline
\end{tabular}

